\title{
Necessary Infrastructure of Infection Prevention and Healthcare Epidemiology Programs: A Review
}

\author{
Kristina A. Bryant, MD; ${ }^{1 a}$ Anthony D. Harris, MD, MPH; ${ }^{2 a}$ Carolyn V. Gould, MD, MSCR; ${ }^{3}$ Eve Humphreys, MBA, CAE; ${ }^{4}$ \\ Tammy Lundstrom, MD, JD; ${ }^{5}$ Denise M. Murphy, RN, BSN, MPH, CIC, FAAN $;{ }^{6}$ Russell Olmsted, MPH, CIC; \\ Shannon Oriola, RN, BSN, CIC; ${ }^{8}$ Danielle Zerr, MD, MPH $^{9}$
}

\section{SUMMARY}

The scope of a healthcare institution's infection prevention and control/healthcare epidemiology program (IPC/HE) should be driven by the size and complexity of the patient population served, that population's risk for healthcare-associated infection (HAI), and local, state, and national regulatory and accreditation requirements. Essential activities of all IPC/HE programs include but are not limited to the following:

- Surveillance

- Performance improvement to reduce HAI

- Acute event response, including outbreak investigation

- Education and training of both healthcare personnel and patients

- Reporting of HAI to the Centers for Disease Control and Prevention's National Healthcare Safety Network as well as entities required by law

An IPC/HE program may be involved in a number of other activities, depending on the needs of the organization, the annual risk assessment, and resources available.

The effective IPC/HE program must be multidisciplinary and include experts in both $\mathrm{HE}$ and infection prevention. Expertise is defined by sets of core competencies established by the Society for Healthcare Epidemiology of America for healthcare epidemiologists and by the Association for Professionals in Infection Control and Epidemiology for infection preventionists. Program personnel must have authority delegated from institutional leadership to perform essential activities and implement change to reduce HAIs. The number of personnel is determined not solely by the number of patients served by a given facility, but rather by the scope and complexity of program activities. The budget allocated for the program must support adequate numbers of personnel (infection preventionists and healthcare epidemiologists) to execute program activities. At present, many healthcare institutions are underresourced, with insufficient reimbursement for hospital epidemiology services and too few infection preventionists. This document provides an updated assessment of the resources and requirements for an effective IPC/HE program.

In 1996, the Society for Healthcare Epidemiology of America (SHEA) convened an expert consensus panel to provide a "best assessment of the needs for a healthy and effective hospital based infection control and epidemiology program." The panel's consensus report was approved by both SHEA and the Association for Professionals in Infection Control and Epidemiology (APIC) and published in 1998. ${ }^{1}$

Nearly 2 decades later, transformative changes have taken place in healthcare and these changes have substantially increased the responsibilities and workload of infection prevention and control (IPC) programs. This evolution has included new challenges for IPC/healthcare epidemiology (hereafter referred to as IPC/HE) programs unheard of at the time of the original publication, including legislative mandates, public reporting, pay-for-performance, payment penalties, healthcare-associated infection (HAI) prevention collaboratives, bioterrorism (anthrax attacks), new and emerging pathogens (systemic acute respiratory distress syndrome, pandemic H1N1 influenza, Middle Eastern respiratory syndrome coronavirus, Ebola virus), Occupational Health and Safety Administration mandates, and the first National Action Plan to reduce HAIs. Concurrently, the rising frequencies of multidrugresistant organisms (MDROs), unprecedented antimicrobial shortages, and a relative lack of new antimicrobials have further tested IPC strategies. ${ }^{2}$ Many of these challenges have

Affiliations: 1. University of Louisville School of Medicine, Louisville, Kentucky; 2. University of Maryland School of Medicine, Baltimore, Maryland; 3. Centers for Disease Control and Prevention, Atlanta, Georgia; 4. Society for Healthcare Epidemiology of America, Arlington, Virginia; 5. Premier Health, Dayton, Ohio; 6. Main Line Health, Philadelphia, Pennsylvania; 7. Trinity Health, Livonia, Michigan; 8. Scripps Memorial Hospital, La Jolla, California; 9. University of Washington, Seattle, Washington.

${ }^{a}$ K.A.B. and A.D.H. contributed equally to this article.

Received December 4, 2015; accepted December 9, 2015; electronically published February 1, 2016

(c) 2016 by The Society for Healthcare Epidemiology of America. All rights reserved. 0899-823X/2016/3704-0001. DOI: 10.1017/ice.2015.333 
TA BLE 1. Goals for Infection Prevention and Control/Healthcare Epidemiology Programs in 2016 and Beyond

1. Protect the patient ${ }^{\mathrm{a}}$

2. Protect healthcare personnel, visitors, and others ${ }^{\mathrm{a}}$

3. Meet accreditation and regulatory mandates

4. Accomplish goals above in as cost-effective manner as possible ${ }^{a}$

${ }^{\mathrm{a}}$ Goals cited in 1998.

necessitated increased education and training. In fact, there is ample evidence that a comprehensive IPC/HE program can reduce $\mathrm{HAI}$, minimize the spread of MDROs, and address emerging infections and pathogens, ultimately keeping patients safer. ${ }^{3,4}$ Thus, the goals for IPC/HE programs noted in Table 1 remain relevant and have added urgency for implementation in a broader array of healthcare settings.

In 2011, the SHEA Guidelines Committee, at the request of the SHEA Board of Directors, convened an expert panel to develop revised consensus recommendations on the key components of an IPC/HE program. The panel included experts in HE, infection prevention, healthcare administration, and public health. Members reviewed relevant literature, other published guidelines, and regulations that impact IPC/ HE programs. The following updated recommendations were developed by debate and consensus during a series of conference calls and vetted by the SHEA Board of Directors. They outline the key activities of such a program, including surveillance, public reporting and compliance with accreditation requirements, acute event response, performance improvement, and education and training, and describe specialized and support personnel required for an effective IPC/HE program. Although these recommendations are largely intended for healthcare facilities in the United States, they follow the general tenets outlined in the World Health Organization document "Core Components for Infection Prevention and Control Programmes."

The new challenges facing IPC/HE programs since the last iteration of this document are highlighted. In contrast to the recommendations published in 1998, the guidance that follows is not intended solely for acute care hospitals but rather has applicability for all healthcare settings. This document also serves as a companion to the core competency documents "Guidance for Infection Prevention and Healthcare Epidemiology Programs: Healthcare Epidemiologist Skills and Competencies" by Kaye et $\mathrm{al}^{5}$ and "Guidance for the Knowledge and Skills Required for Antimicrobial Stewardship Leaders" by Cosgrove et $\mathrm{al}^{6}{ }^{6}$ and it complements the work of Moody et al, "Antimicrobial Stewardship: A Collaborative Partnership Between Infection Preventionists and Healthcare Epidemiologists.”

\section{CORE ACTIVITIES OF THE IPC/HE PROGRAM}

\section{Surveillance}

Surveillance (case finding), data collection and analysis, and reporting these findings are the critical functions of IPC.
Surveillance data not only define the problem but are used to drive improvement and, historically, are a foundation for infection prevention programs. ${ }^{8}$ What constitutes appropriate surveillance for a given healthcare setting is a complex question that is increasingly influenced by external forces. Outcome data (eg, central line-associated bloodstream infection [CLABSI] rates) and process data (eg, timely surgical antimicrobial prophylaxis) are both potentially among the "what" to collect, while the "who" involves the targeted patient population. Risk assessment is the cornerstone of the decisionmaking process used to design an organization-specific surveillance program and involves identifying the most important populations and infections to follow so that resources can be focused on the most worthwhile prevention activities. "Important" typically translates into those populations most vulnerable to HAIs; infections that cause the highest morbidity, mortality, and expenditure of healthcare resources; the organisms that are most concerning for populations the facility serves, including MDROs; and organisms most likely to put healthcare personnel (HCP) at risk for disease. By necessity, the risk assessment must also consider requirements of external agencies, payers such as Centers for Medicare \& Medicaid Services (CMS), and state-based legislative mandates. 9,10

\section{Public Reporting and Meeting Accreditation Requirements}

The 1999 Institute of Medicine report "To Err Is Human" focused public attention on the morbidity and mortality associated with HAIs. ${ }^{11}$ Recognition that many HAIs could be prevented and consumer demand for safer healthcare helped fuel an increase in the number and complexity of regulatory and legislative mandates surrounding HAIs. As of March 2014, a total of 31 states had enacted laws that require hospitals and sometimes other healthcare facilities to report HAI data to the National Healthcare Safety Network. ${ }^{12}$ The CMS Conditions of Participation for Hospitals and its Conditions for Coverage for Ambulatory Surgery Centers, both conditions that healthcare organizations must meet in order to be Medicare- and Medicaid-certified and receive reimbursement, include requirements for "active programs for the prevention, control and investigation of infections and communicable disease."13 Accrediting organizations such as the Joint Commission, the American Osteopathic Association, and Det Norske Veritas provide detailed standards on infection prevention expected of providers seeking accreditation. Meeting these regulatory and accreditation requirements along with increasingly frequent legislative mandates for HAI data requires a substantial investment of resources and is a key element of an effective IPC/HE program. In addition, CMS, under its inpatient quality reporting, is currently requiring acute care providers to report CLABSI, catheter-associated urinary tract infections, and select surgical site infections, as well as hospital-onset Clostridium difficile infection and hospital onset methicillinresistant Staphylococcus aureus bloodstream infection, while 
long-term care hospitals, skilled nursing facilities, acute care cancer hospitals, and inpatient rehabilitation facilities are also required to report specific HAIs. The Affordable Care Act provisions include a mandate that facilities within the highest quartile for certain infections be penalized $1 \%$ of their Medicare reimbursement. Despite concerns over revenue loss, collaboration with legislators and consumers is a critical part of efforts to promote prevention, ultimately leading to improved patient safety and better patient outcomes.

\section{Acute Event Response}

The 1998 consensus panel report noted that "the most common setting in which infection preventionists (IPs) and hospital epidemiologists intervene directly in patient-care activities is in the control of an outbreak of nosocomial infections." Outbreak identification, investigation and management remains a key function of IPC/HE programs and may require a significant proportion of a program's resources. Additionally, emergency preparedness and response is a related but distinct function of most programs and may be associated with novel or emerging pathogens, agents of bioterrorism, or infectious disease outbreaks following natural disasters. ${ }^{14}$

\section{Performance Improvement}

The power and efficacy of HAI surveillance lies in sharing findings with direct care providers who can use such findings to improve the safety and quality of care. Performance or process improvement initiatives can help busy healthcare teams to integrate prevention measures into their daily practice and ultimately reduce HAIs. Understanding, leading, and facilitating process improvement using methods such as "plan, do, study, act," "plan, do, check, act," or more recently the 4Es model ("engage, educate, execute, evaluate") are key functions of contemporary IPC/HE programs. ${ }^{15}$ Process mapping and other tools are used to identify and remove barriers to effective systems and processes that impact outcomes of care. Tools to eliminate waste and reduce process variation, such as Lean and Six Sigma, have been adopted from other industries to create more efficient work flows and improve adoption of practices that reduce HAIs. Process improvement initiatives may be driven by suboptimal results identified by surveillance or process data or during annual risk assessment and plan evaluation, an organization's strategic priorities, as well as regulatory and accreditation requirements.

\section{Education and Training}

Education and training of HCP are critical functions to prevent HAIs and core functions of IPC/HE programs. Regulatory and accreditation agencies such as CMS, the Occupational Health and Safety Administration, and the Joint Commission require routine training in infection prevention, ${ }^{16,17}$ and focused training for various disciplines has been effective in achieving sustained reductions in HAIs. ${ }^{18}$ Nevertheless, there is increasing recognition of the need for improved education and oversight among HCP in a variety of settings. Ongoing lapses and major errors in infection prevention efforts, including injection safety practices, resulting in outbreaks of bloodborne pathogens (eg, hepatitis B and C), particularly in outpatient settings, demonstrate a lack of basic infection prevention practice and processes in many cases. ${ }^{17,19}$ A survey of ambulatory surgical centers found that infection prevention lapses were common and included breaches such as reuse of single-dose vials for multiple patients and errors in reprocessing of equipment. ${ }^{20}$ Continued transmission of MDROs and influenza in healthcare settings resulting from poor adherence to hand hygiene and other infection control measures also demonstrates a need to reevaluate the educational approach.

Experts in IPC/HE should lead curriculum development for HCP infection prevention education. Routine in-service training should be directed toward HCP of all disciplines, including physicians, nurses (registered nurses, licensed practical nurses), and other HCP with direct or indirect contact with patients or equipment (eg, environmental services workers, instrument reprocessing staff, dietary personnel) and should be tailored to the appropriate educational level, learning styles, and work duties. This training should incorporate evidence-based practices to reduce HAIs, including hand hygiene and all tasks for which personnel are responsible, and incorporate assessment of well-defined competencies for each task. ${ }^{21}$ Because targeting specific educational programs at clinicians-in-training has been an effective way to improve practice and reduce the risk of HAIs, ${ }^{22}$ medical students, nursing students, and other trainees working in a facility should receive instruction about HAI prevention. Carrico et $\mathrm{al}^{23}$ outline a set of IPC competencies for all HCP that may serve as the basis for training programs in a variety of educational settings.

IPC/HE programs must also provide education for patients and their families. The need to educate patients about HAIs and how to prevent them is highlighted in the 2013 Health and Human Services National Action Plan to Prevent HealthcareAssociated Infections: Road Map to Elimination. ${ }^{24}$ Specifically, education of patients, family members, and visitors on infection prevention measures, particularly hand hygiene, standard precautions, and transmission-based precautions as appropriate, is a key element in preventing transmission of pathogens in healthcare settings. ${ }^{10,25}$ The Joint Commission National Patient Safety Goals require healthcare providers to educate patients (and their families as needed) who are infected or colonized with an MDRO about HAI prevention strategies; the National Patient Safety Goals also require education specific to CLABSI prevention before insertion of a central venous catheter as well as education related to surgical site infection prevention before a surgical procedure (NPSG.07.03.01 EP \#3, NPSG.07.04.01 EP \#3, NPSG.07.05.01 EP \#2). IPC/HE personnel may develop educational materials to be used by clinical staff or may serve as educators for patients and their families. 


\section{ADJUNCT ACTIVITIES OF THE IPC/HE PROGRAM}

\section{Collaboration With Employee Health Services}

HCP are frequently exposed to communicable diseases and those who develop infections may pose a risk to other HCP as well as patients. The effective IPC/HE program collaborates with employee/occupational health services to ensure the health and safety of HCP in a facility. Examples of collaboration may include but are not limited to establishing pre-employment/pre-credentialing health screening and immunization requirements, notification and postexposure management protocols for HCP exposed to communicable diseases in the healthcare setting, assistance with decisions about postexposure prophylaxis, sharps injury prevention programs and evaluation of new safety devices, return to work policies (after communicable diseases), syndromic surveillance of absentees, and facility response to community outbreaks. Many IPC/HE programs are actively involved in employee immunization initiatives, including annual influenza vaccination campaigns.

\section{Antibiotic Stewardship}

Antibiotic use is a risk factor for the development of infections with MDROs, including methicillin-resistant $S$. aureus, vancomycin-resistant enterococci, and carbapenem-resistant Enterobacteriaceae, as well as other common healthcareassociated pathogens such as $C$. difficile. Accordingly, antibiotic stewardship programs (ASPs) are increasingly a core HAI prevention strategy-especially given the lack of significant development of new classes of antimicrobials to treat infections caused by MDROs. ${ }^{26-28}$ In 2014, the Centers for Disease Control and Prevention recommended that all acute care hospitals implement $\mathrm{ASPs}^{29}$ and described the core elements of such programs (http://www.cdc.gov/getsmart/ healthcare/implementation/core-elements.html). Legislative mandates may drive more programs to adopt antibiotic stewardship as a core activity. California already requires healthcare facilities to have ASPs. ${ }^{10}$ In September 2014, the President's Council of Advisors on Science and Technology recommended that CMS implement new Conditions of Participation by the end of the 2017, requiring "hospitals, critical access hospitals, and long-term care and nursing home facilities to develop and implement robust antibiotic stewardship programs that adhere to best practices." 30 Revised CMS Conditions of Participation for both long-term care and acute care settings are expected in spring 2016.

Evidence-based guidelines from SHEA and the Infectious Diseases Society of America recommend that a healthcare facility's stewardship team include the hospital epidemiologist, clinical pharmacist, clinical microbiologist, and IP. ${ }^{31}$ The ASP, in particular, is a key partner program wherein the physician involved in infection prevention can champion appropriate guideline adaptation in individual facilities, thereby reducing and preventing emergence of antimicrobial resistance. ${ }^{32}$
A more detailed description of the critical skills and knowledge needed for leaders of ASPs can be found in the articles by Cosgrove et $\mathrm{al}^{6}$ and Moody et al. ${ }^{7}$

\section{Participation in Regional and National Collaboratives}

Over the past decade, many national campaigns and multicenter collaboratives have influenced infection prevention efforts and driven reductions in HAIs, especially deviceassociated infections. The 100,000 Lives Campaign, launched by the Institute for Healthcare Improvement in December 2004, ultimately engaged 3,100 hospitals in the prevention of CLABSI, surgical site infection, and ventilator-associated pneumonia through application of evidenced-based prevention "bundles." Regional or statewide projects such as the Pittsburgh Regional Healthcare Initiative and the Michigan Keystone Project demonstrated an approximately $70 \%$ reduction in CLABSI through adherence to evidence-based best practices for central line insertion. ${ }^{33}$ Similarly, the National Association of Children's Hospitals and Related Institutions sponsored a multicenter collaborative focused on CLABSI reduction in children. ${ }^{34}$ Participation in a multicenter infection prevention collaborative requires an investment of time, resources, and expertise by IPs and hospital epidemiologists, who are called on to help lead multidisciplinary process improvement teams, educate front line staff as well as senior leadership, and implement tests of change. A critical factor common to the success of these improvement collaboratives was commitment by leadership to assess and improve the culture of safety among their workforce. Participation may increase data collection requirements and impact an institution's surveillance plan but will often boost the visibility of the IPC/HE team members as organizational leaders.

\section{RESOURCES NECESSARY FOR THE IPC/HE PROGRAM}

The personnel, physical, and financial resources required for an effective IPC/HE program should be proportional to the size, sophistication, case mix, and estimated infection risk of the populations served by the institution. The individual(s) responsible for leadership of the program must be clearly identified and have significant access to key organizational leaders and clinical decision makers. ${ }^{35,36}$

Federal and state agencies as well as accreditation organizations require institutions to clearly identify the individual with program authority and responsibility. Specifically, CMS Conditions of Participation $\$ 482.42(\mathrm{a})$ states, “A person or persons must be designated as infection control officer or officers to develop and implement policies governing control of infections and communicable diseases." During a CMS survey, a surveyor will determine whether an infection control officer(s) is designated by the organization's leadership and has the responsibility for the infection prevention program. This responsibility needs to be accompanied by evidence of adequate support and infrastructure that facilitates an effective 
infection prevention program. The interpretive guidelines for $\$ 482.42$ (b) state that it is the responsibility of the chief executive officer, the medical staff, and the director of nursing to implement successful corrective action plans for problems identified through the infection prevention program. The survey procedure includes a determination of whether infection prevention problems identified are reported to the medical staff, chief executive officer, chief nursing officer, and the board. It is essential that infection prevention personnel work closely with senior leadership when addressing quality assessment and performance improvement. In fact, CMS Conditions of Participation require that the infection prevention program be integrated into the broader quality improvement program.

Similarly, the Joint Commission Standard IC.01.01.01 requires an individual with clinical authority over the infection prevention program to have responsibility for developing a system for identifying, reporting, investigating, and controlling infections and communicable diseases. The same standard requires that when the individual(s) with clinical authority over the IPC/HE program does not have expertise in IPC, he or she consults with someone who has such expertise in order to make knowledgeable decisions. ${ }^{37}$ State licensing requirements may also designate that an individual with a specific skill set or training have authority over the infection prevention program.

\section{Personnel Resources}

The Healthcare Epidemiologist. The importance of physician leadership in IPC/HE program was recognized as early as the 1960s when published conceptual models called for a physician "infection control officer" to perform most surveillance and control activities. The Study on the Efficacy of Nosocomial Infection Control project, conducted by the Centers for Disease Control and Prevention, identified that a physician with training in $\mathrm{HE}$ is an essential component of a hospital infection prevention program and programs led by a physician with expertise in HE had lower rates of HAIs. ${ }^{8,38}$ Today, physicians who fill the role of healthcare epidemiologist/medical director of infection prevention may share oversight of a facility's infection prevention program with an IP manager/leader. Duties of hospital epidemiologist/IP teams often include strategic planning, leadership of quality/performance improvement initiatives, and communication with facility administrators.
Healthcare epidemiologists are typically physicians with subspecialty training in infectious diseases and a background in internal medicine or pediatrics. Today, healthcare epidemiologists may also include professionals from fields other than medicine (eg, nursing or clinical microbiology specialists with graduate degrees in public health). At present, there is no national certification process for healthcare epidemiologists, although 1 state, California, has mandatory minimum requirements for physicians who have authority over the IPC program (https://www.cdph.ca.gov/services/boards/Documents/SB158chaptered09_25_08.pdf). A detailed review of the core competencies needed for healthcare epidemiologists can be found in the recent article by Kaye et al. ${ }^{5}$

Formal recommendations regarding hospital epidemiologist staffing remain rare, although in the Netherlands, a recommendation was made to the Society for Infectious Diseases to adopt a level of 1 full-time equivalent epidemiologist per 25,000 admissions. In a recent nationwide survey, released in 2014, that included hospitals participating in the Centers for Disease Control and Prevention's National Healthcare Safety Network, $49.6 \%$ of the respondents employed a physician hospital epidemiologist. ${ }^{39}$ An earlier study with a similar percent of hospitals reporting a physician HE (ie, 49\%) showed that the mean number of dedicated hours per week was far less than an FTE (mean hours, 12). ${ }^{36}$ These data highlight an unmet need for physician epidemiology support in many hospitals. Financial resources need to be committed so that far greater hours are committed to a physician hospital epidemiologist than this survey currently reflects. The increased hours spent by the hospital epidemiologist lead to improved patient care.

Healthcare epidemiologists/medical directors should be compensated adequately and appropriately for their work by the healthcare facility or entity using their services. A recent survey of SHEA members indicated that traditional hospital epidemiology and infection control activities are compensated at levels not commensurate with the actual time dedicated to these services. ${ }^{40}$ McQuillen et $\mathrm{al}^{32}$ describe a suggested framework for the hospital epidemiologist to negotiate appropriate compensation for managing IPC activities.

With the list of activities that the healthcare epidemiologist performs and the increasing requirements over the past decade, recommendations for staffing and financial compensation are listed in Table 2.

TAвLE 2. Healthcare Epidemiologist/Medical Director-Recommended Resource Allocation

\begin{tabular}{|c|c|c|}
\hline Variable & Hospital has $\geq 300$ beds and/or $\geq 50$ ICU beds & Hospital has $<300$ beds and/or $<50$ ICU beds \\
\hline $\begin{array}{l}\text { Academic-based } \\
\text { institutions }\end{array}$ & $\begin{array}{l}\geq 1.5 \text { FTE of full professor salary (based on AAMC salary } \\
\text { compensation) towards infection control }\end{array}$ & $\begin{array}{l}\geq 1 \text { FTE of full professor salary towards infection } \\
\text { control }\end{array}$ \\
\hline
\end{tabular}

NOTE. AAMC, Association of American Medical Colleges; FTE, full-time equivalent; ICU, intensive care unit.

${ }^{\mathrm{a}}$ This reimbursement should allow protected time for the hospital epidemiologist to perform these activities. 
The IP. The Study on the Efficacy of Nosocomial Infection Control also identified that IPs (formerly known as infection control practitioners or ICPs), many of whom were nurses, were essential components of an effective program. ${ }^{8}$ This assertion is supported by more recent studies that found that facilities with a certified IP are more likely to implement prevention practices for CLABSI ${ }^{41}$ and catheter-associated urinary tract infection ${ }^{42}$ and to report lower frequencies of MDROs such as methicillin-resistant $S$. aureus. ${ }^{43}$

Professional and practice standards for IPs have been published by a number of organizations, including APIC, Infection Prevention and Control Canada (formerly CHICA-Canada), Certification Board of Infection Control and Epidemiology, ${ }^{44}$ and the Infection Prevention Society in the United Kingdom. APIC has also developed a conceptual model of competency for the novice, proficient, and expert IP. ${ }^{45}$ To meet the demands of the rapidly expanding field of infection prevention and to equip professionals for the challenges of the future, APIC created the first model for IP competency in 2012. The model outlines the skills needed to advance the infection prevention field and was created to help direct the IP's professional development at all career stages. ${ }^{46}$

Core competencies as identified through practice analyses by the Certification Board of Infection Control and Epidemiology include proficiency in identification of infectious disease processes; surveillance and epidemiologic investigation; preventing/controlling the transmission of infectious agents; employee occupational health; leadership ability; and concepts of education and research. Additional futureoriented competencies include leadership, IPC, technology, and performance improvement/implementation science. Certification in IPC (called CIC) is a nationally recognized standard for validating competency of the IP.

Over the past several decades, the amount and complexity of the IP's work has increased dramatically (Table 3) and many IPs now provide oversight to an expanding network of affiliated ambulatory care facilities in addition to the core inpatient facility. The complexity and intensity of patient care delivery, increasing severity of illness of the patient population at risk and use of invasive devices, increasing activity related to the delivery of healthcare beyond the traditional hospital walls, and mandatory reporting of HAIs are only a few of the reasons for the expansion of the IP's responsibilities. ${ }^{47}$ In summer 2015, APIC conducted a workforce survey (aka MegaSurvey) of its members to understand the current state of IP demographics, IPC organizational structure, IP practice and competencies, and IP compensation. A summary of these data is expected to be published in 2016. These data will also help guide the optimal number of IPs for different settings.

Additional Support Personnel. The need for personnel to support administrative tasks and help manage the IPC/HE program remains unchanged since the initial publication of this consensus report. This support is critically important as it permits delegation of administrative tasks so that the hospital epidemiologists and IPs can focus on driving improvement.
The recommendation to develop data analysis expertise within IPC/HE programs is further supported by newly required HAI reporting to payers and consumers. Such administrative support may be available routinely in larger facilities, but less so in smaller facilities that are more typical of acute care hospitals in the United States. One possible strategy for developing and acquiring these personnel may be to share resources within a broader scope of similar services that are aimed at patient safety (eg, process improvement, accreditation, or risk management departments). Another strategy involves an analysis of tasks performed by the personnel in infection prevention and matching these with skills and backgrounds of support personnel to optimize program efficiency and cost-effectiveness.

IPC Liaison. Designating health professionals involved in direct patient care as IPC liaisons or "link nurses" has been reported to be an effective adjunct to enhance IPC at the unit level. ${ }^{48-51}$ Such individuals receive training in essential elements of IPC and have frequent communication with the IPC/HE program but maintain their primary role as direct caregivers in the areas they work. Liaisons can facilitate awareness of IPC at the point of care and assist with implementation of new policy, intervention, or practice changes; provide point of care education; and share surveillance findings. Liaisons can serve as an adjunct to, but not a replacement for, fully trained IPs, and liaison nurses should not be considered when assessing IP staffing.

\section{Physical Resources}

The IPC/HE program should have sufficient office space to support the functions of the personnel who oversee the program. Ideally, this office space will be located near clinical units to allow for frequent interaction with frontline providers and medical staff, assessment of compliance with infection prevention processes, and observation of the environment of care.

Information Technology and Health Informatics. An essential deliverable of HAI surveillance is to provide findings to direct care providers and support services personnel, as well as to the patients seeking care. As such, IPC/HE programs are now tasked with significant escalation in the collation, analysis, and timely reporting of surveillance data. Informatics systems and networks are an increasingly critical element of the program infrastructure.

IPC/HE programs are meeting these increasing informatics needs with homegrown systems that require resources for construction and maintenance. In addition, many sites have purchased third party infection control vendors that enhance existing electronic medical records and homegrown systems. Applications that can tie a laboratory information system, admission/discharge/transfer, imaging results systems, pharmacy, microbiology, and so on into a single data network are needed by IPC/HE programs. Well-run systems increase the efficiency of the HAI surveillance system. Eliminating manual review of microbiology reports or other paper records frees up 
тав Le 3. Trends in Growing Roles and Responsibilities of the Infection Prevention Program, 1970-2016, United States

\begin{tabular}{|c|c|c|}
\hline Variable & $\begin{array}{l}\text { Infection prevention programs of the 1970s- } \\
\text { early } 1990 \mathrm{~s}\end{array}$ & Infection prevention programs of 2016 \\
\hline Scope of program & Focused on infectious disease events & $\begin{array}{l}\text { Focused on other quality and safety outcomes (eg, surgical } \\
\text { antimicrobial prophylaxis, leading immunizations for patients } \\
\text { and employee occupational health programs) and preparedness } \\
\text { such as pandemic planning. }\end{array}$ \\
\hline Scope of surveillance & Surveillance of acute care setting—often ICU & $\begin{array}{l}\text { Expanded into non-intensive care unit settings setting as well as } \\
\text { ambulatory settings. }\end{array}$ \\
\hline Data collection & $\begin{array}{l}\text { Medical record review abstracted from paper } \\
\text { chart review }\end{array}$ & $\begin{array}{l}\text { Data mining of electronic medical record with flagging capability } \\
\text { of possible HAIs. }\end{array}$ \\
\hline $\begin{array}{l}\text { Reporting data to NNIS/ } \\
\text { NHSN }\end{array}$ & $\begin{array}{l}300 \text { hospitals reporting to NNIS- } \\
\text { nonparticipating hospitals could compare } \\
\text { their rates with participating hospitals }\end{array}$ & $\begin{array}{l}>5,000 \text { hospitals reporting to NHSN with ability to analyze data } \\
\text { within system. CMS and } 31 \text { states have access to obtain certain } \\
\text { outcome data. }\end{array}$ \\
\hline Education & $\begin{array}{l}\text { Education related to regulatory requirements } \\
\text { (Occupational Safety and Health } \\
\text { Administration for bloodborne pathogens, } \\
\text { isolation, etc.) }\end{array}$ & $\begin{array}{l}\text { Greater focus on patient safety/quality improvement: participation } \\
\text { in collaboratives such as CUSP and IHI. }\end{array}$ \\
\hline Resources & $\begin{array}{l}\text { Infection control program staffed with limited } \\
\text { resources }\end{array}$ & $\begin{array}{l}\text { Focused on building a business case for additional resources: IPs, } \\
\text { product acquisition with supporting evidence of HAI reduction. }\end{array}$ \\
\hline Environmental rounding & $\begin{array}{l}\text { Environmental rounding to meet regulatory } \\
\text { requirements }\end{array}$ & $\begin{array}{l}\text { Expanded to include construction risk assessment, evaluation of } \\
\text { injection safety practices, hand hygiene compliance, evaluation } \\
\text { of sterilization and high-level disinfection practices, quality } \\
\text { assurance of environmental cleaning. }\end{array}$ \\
\hline
\end{tabular}

NOTE. CMS, Centers for Medicare and Medicaid Services; CUSP, Comprehensive Unit-based Safety Program; HAI, healthcare-associated infection; ICU, intensive care unit; IHI, Institute for Healthcare Improvement; NHSN, National Healthcare Safety Network; NNIS, National Nosocomial Infection Surveillance System.

the IP for more collaboration with clinicians and allows them to embark on other endeavors that may have the greatest impact on patient outcomes.

Widespread use of the electronic health record, fueled by CMS's Health Information Technology incentives and standards for Meaningful Use, may improve efficiency by facilitating algorithmic detection of HAIs. ${ }^{52}$ Algorithmic detection of potential HAIs can offer similar, and in some instances superior, sensitivity and specificity in the application of the National Healthcare Safety Network HAI surveillance criteria in less time. ${ }^{53}$ In 1 study, algorithmic detection using the electronic health record reduced the amount of time for an IP to manually review and abstract laboratory data for application of catheter-associated urinary tract infection criteria by more than $97 \%{ }^{54}$ It should be noted that such applications in electronic health records are uncommon and often require extensive local build and validation. A comprehensive review of electronic surveillance methods has recently been published by Woeltje $\mathrm{j}^{55}$ that provides more detailed description about advanced informatics and the IPC/HE program.

Education, Data, and Report Presentation. IPs should have access to equipment and communication channels at the organization that support essential education and surveillance goals.

\section{ADDITIONAL COLLABORATIVE RELATIONSHIPS}

The effective IPC/HE program works collaboratively with other departments within an organization as well as with public health authorities. 
Without appropriate funding, IPC/HE programs will be unable to perform effectively. Finance and accounting departments can assist in the preparation of the business case for IPC/HE program resources as they will have access to data about dollars lost due to HAI through pay-for-performance and penalty programs. They can promote understanding of the return on investment of the IPC/HE program.

IPC/HE programs need to develop close working relationships with risk management and legal departments. Risk management involvement should follow facility policy, and their involvement may be necessary for institutional outbreaks, HAIs requiring a root cause analysis, or patient exposure to contaminated supplies or equipment, for example. Many facilities use incident reports as another case-finding method for surveillance, and these programs are frequently managed by the risk management or legal department. Close working relationships ensure that the facilities' legal interests are protected in the event of malpractice action. In addition, department staff can help drive proactive HAI reduction efforts. The department can also be a source of information regarding reimbursement dollars lost due to HAIs, which can be useful in preparing a business case for IPC/ HE programs.

An effective prevention program is a key component of an institutional patient safety program. Although the goals of an IPC/HE program are aligned with those of the quality department, the skill set, training, expertise, and core functions are distinct. Because IPs and hospital epidemiologists frequently have specialized training in process improvement, they can often serve as a resource for design and implementation of quality improvement projects not specifically related to infection prevention.

Marketing and communications (sometimes referred to as media relations or public relations) is another department that can be used to augment IPC/HE program activities. In larger facilities they may be responsible for internal communications, which can help drive the infection prevention program's messages through newsletters, screen savers, Internet pages, podcasts, social media, and other internal communications channels. They can assist in preparation and standardization of patient and family informational activities and provide expertise in preparing media responses to queries regarding outbreaks, public facility HAI information, and public reports citing facility HAI rates.

Patient (or consumer) relations is another important collaborative department. They may receive concerns from patients and/or family members regarding HAI events via communications with a patient ombudsman, especially in this era of public awareness of HAIs.

Finally, it is extremely important to develop close working relationships with local and state public health departments as true partners in HAI prevention. These agencies can serve as valuable consultants in the event of facility or communitywide outbreaks and provide much-needed guidance in evolving outbreaks attributed to novel pathogens. In addition, they are often in the forefront of HAI reduction collaboratives in association with state hospital associations.

\section{CONCLUSIONS}

The work of IPC/HE has changed dramatically over the past 2 decades. This has led to increased workload and demands without commitment of additional resources. At present, many healthcare institutions are underresourced, with insufficient reimbursement for hospital epidemiology services and too few IPs. This document provides an updated assessment of the requirements for an effective IPC/HE program, which can be used as a touchstone when determining appropriate structure, activities, and resources. Taken with its companion documents that address the competencies necessary for healthcare epidemiologists ${ }^{5}$ and leaders of antimicrobial stewardship programs ${ }^{6}$ as well as information system needs, ${ }^{55}$ these recommendations will assist existing programs in evaluating potential gaps or weaknesses and provide new programs with a framework on which to build.

\section{ACKNOWLEDGMENTS}

We gratefully acknowledge Tom Talbot, MD, MPH, Sharon B. Wright, MD, MPH, and Louise-Marie Dembry, MD, MS, MPH, for their thoughtful review and suggestions, and Kristy Weinshel, MBA for editorial support.

Financial support. None reported.

Potential conflicts of interest. All authors report no conflicts of interest relevant to this article.

Disclaimer: The findings and conclusions in this report are those of the authors and do not necessarily represent the official position of the Centers for Disease Control and Prevention.

Address correspondence to Kristina A. Bryant, MD, Pediatric Infectious Diseases, 571 S Floyd St, Ste 321, Louisville, KY 40202 (K0brya01@louisville.edu).

\section{REFERENCES}

1. Scheckler WE, Brimhall D, Buck AS, et al. Requirements for infrastructure and essential activities of infection control and epidemiology in hospitals: a consensus panel report. Infect Control Hosp Epidemiol 1998;19:114-124.

2. Bartlett JG. A call to arms: the imperative for antimicrobial stewardship. Clin Infect Dis 2011;53:S4-S7.

3. Kochar S, Sheard T, Sharma R, et al. Success of an infection control program to reduce the spread of carbapenem-resistant Klebsiella pneumoniae. Infect Control Hosp Epidemiol 2009;30:447-452.

4. Ebnother C, Tanner B, Schmid F, La Rocca V, Heinzer I, Bregenzer T. Impact of an infection control program on the prevalence of nosocomial infections at a tertiary care center in Switzerland. Infect Control Hosp Epidemiol 2008;29:38-43.

5. Kaye KS, Anderson DJ, Cook E, et al. Guidance for infection prevention and healthcare epidemiology programs: healthcare epidemiologist skills and competencies. Infect Control Hosp Epidemiol 2015;36:369-380.

6. Cosgrove SE, Hermsen ED, Rybak MJ, et al. Guidance for the knowledge and skills required for antimicrobial stewardship leaders. Infect Control Hosp Epidemiol 2014;35:1444-1451. 
7. Moody J, Cosgrove SE, Olmsted R, et al. Antimicrobial stewardship: a collaborative partnership between infection preventionists and health care epidemiologists. Am J Infect Control 2012;40:94-95.

8. Haley RW, Culver DH, White JW, et al. The efficacy of infection surveillance and control programs in preventing nosocomial infections in US hospitals. Am J Epidemiol 1985;121:182-205.

9. Medicare program. Fed Regist 2013;78:50495-51040.

10. California Senate bill no. 158. 2008. California Legislative website. http://www.leginfo.ca.gov/pub/07-08/bill/sen/sb_0151-0200/sb_ 158_bill_20080925_chaptered.pdf. Published 2008. Accessed April 14, 2014.

11. Kohn L, Corrigan J, Donaldson M. To Err Is Human: Building a Safer Health System. Washington, DC: Institute of Medicine; 2000.

12. State-based HAI prevention. Centers for Disease Control and Prevention website. http://www.cdc.gov/hai/stateplans/required-toreport-hai-NHSN.html. Published 2014. Accessed April 14, 2014.

13. Conditions of participation for hospitals. US Government Publishing Office website. http://www.ecfr.gov/cgi-bin/text-idx? tpl=/ecfrbrowse/Title42/42cfr482_main_02.tpl. Published 2015. Accessed April 14, 2015.

14. Rebmann T, English JF, Carrico R. Disaster preparedness lessons learned and future directions for education: results from focus groups conducted at the 2006 APIC Conference. Am J Infect Control 2007;35:374-381.

15. Saint S, Howell JD, Krein SL. Implementation science: how to jump-start infection prevention. Infect Control Hosp Epidemiol 2010;31:S14-S17.

16. Hoffmann K, Clontz E. Education of healthcare workers in the prevention of healthcare-associated infections. In: Hospital Epidemiology and Infection Control, 3rd ed. Baltimore, MD: Williams and Wilkens, 2004:1755-1764.

17. Perz JF, Thompson ND, Schaefer MK, Patel PR. US outbreak investigations highlight the need for safe injection practices and basic infection control. Clin Liver Dis 2010;14:137-151.

18. Warren DK, Zack JE, Mayfield JL, et al. The effect of an education program on the incidence of central venous catheter-associated bloodstream infection in a medical ICU. Chest 2004;126: 1612-1618.

19. Thompson ND, Perz JF, Moorman AC, Holmberg SD. Nonhospital health care-associated hepatitis $\mathrm{B}$ and $\mathrm{C}$ virus transmission: United States, 1998-2008. Ann Intern Med 2009;150:33-39.

20. Schaefer MK, Jhung M, Dahl M, et al. Infection control assessment of ambulatory surgical centers. JAMA 2010;303:2273-2279.

21. Mulder H, Cate OT, Daalder R, Berkvens J. Building a competency-based workplace curriculum around entrustable professional activities: the case of physician assistant training. Med Teach 2010;32:e453-e459.

22. Sherertz RJ, Ely EW, Westbrook DM, et al. Education of physicians-in-training can decrease the risk for vascular catheter infection. Ann Intern Med 2000;132:641-648.

23. Carrico RM, Rebmann T, English JF, Mackey J, Cronin SN. Infection prevention and control competencies for hospitalbased health care personnel. Am J Infect Control 2008;36:691-701.

24. National action plan to prevent health care-associated infections: road map to elimination. US Department of Health and Human Services website. http://www.health.gov/hai/prevent_hai. asp\#hai_plan. Published 2013. Accessed October 1, 2015.

25. Siegel JD, Rhinehart E, Jackson M, Chiarello L, Healthcare Infection Control Practices Advisory Committee.2007, guideline for isolation precautions: preventing transmission of infectious agents in healthcare settings. CDC website. http://www.cdc.gov/ ncidod/dhqp/pdf/isolation2007.pdf. Updated September 15, 2015. Accessed December 22, 2015.

26. Boucher HW, Talbot GH, Bradley JS, et al. Bad bugs, no drugs: no ESKAPE! An update from the Infectious Diseases Society of America. Clin Infect Dis 2009;48:1-12.

27. Calfee DP, Salgado CD, Classen D, et al. Strategies to prevent transmission of methicillin-resistant Staphylococcus aureus in acute care hospitals. Infect Control Hosp Epidemiol 2008;29:S62-S80.

28. Dubberke ER, Gerding DN, Classen D, et al. Strategies to prevent Clostridium difficile infections in acute care hospitals. Infect Control Hosp Epidemiol 2008;29:S81-S92.

29. Fridkin S, Baggs J, Fagan R, et al. Vital signs: improving antibiotic use among hospitalized patients. MMWR Morb Mortal Wkly Rep 2014;63:194-200.

30. Report to the President on Combating Antibiotic Resistance. White House website. http://1.usa.gov/1qhDgF6. Published 2014. Accessed September 30, 2014.

31. Dellit TH, Owens RC, McGowan JE Jr, et al. Infectious Diseases Society of America and the Society for Healthcare Epidemiology of America guidelines for developing an institutional program to enhance antimicrobial stewardship. Clin Infect Dis 2007;44:159-177.

32. McQuillen DP, Petrak RM, Wasserman RB, Nahass RG, Scull JA, Martinelli LP. The value of infectious diseases specialists: non-patient care activities. Clin Infect Dis 2008;47:1051-1063.

33. Centers for Disease Control and Prevention. Vital signs: central line-associated blood stream infections-United States, 2001, 2008, and 2009. MMWR Morb Mortal Wkly Rep 2011;60: 243-248.

34. Miller MR, Griswold M, Harris JM 2nd, et al. Decreasing PICU catheter-associated bloodstream infections: NACHRI's quality transformation efforts. Pediatrics 2010;125:206-213.

35. Garcia R, Barnard B, Kennedy V. The fifth evolutionary era in infection control: interventional epidemiology. Am J Infect Control 2000;28:30-43.

36. Stone PW, Dick A, Pogorzelska M, Horan TC, Furuya EY, Larson E. Staffing and structure of infection prevention and control programs. Am J Infect Control 2009;37:351-357.

37. Hospital Accreditation Standards. The Joint Commission; 2011.

38. Haley RW, Morgan WM, Culver DH, et al. Update from the SENIC project. Hospital infection control: recent progress and opportunities under prospective payment. Am J Infect Control 1985;13:97-108.

39. Stone PW, Pogorzelska-Maziarz M, Herzig CT, et al. State of infection prevention in US hospitals enrolled in the National Health and Safety Network. Am J Infect Control 2014;42:94-99.

40. Wright SB, Ostrowsky B, Fishman N, Deloney VM, Mermel L, Perl TM. Expanding roles of healthcare epidemiology and infection control in spite of limited resources and compensation. Infect Control Hosp Epidemiol 2010;31:127-132.

41. Krein SL, Hofer TP, Kowalski CP, et al. Use of central venous catheter-related bloodstream infection prevention practices by US hospitals. Mayo Clin Proc 2007;82:672-678.

42. Saint S, Kowalski CP, Kaufman SR, et al. Preventing hospitalacquired urinary tract infection in the United States: a national study. Clin Infect Dis 2008;46:243-250.

43. Pogorzelska M, Stone PW, Larson EL. Certification in infection control matters: impact of infection control department 
characteristics and policies on rates of multidrug-resistant infections. Am J Infect Control 2012;40:96-101.

44. Friedman C, Curchoe R, Foster M, et al. APIC/CHICA-Canada infection prevention, control, and epidemiology: professional and practice standards. Am J Infect Control 2008;36:385-389.

45. Murphy DM, Hanchett M, Olmsted RN, et al. Competency in infection prevention: a conceptual approach to guide current and future practice. Am J Infect Control 2012;40:296-303.

46. Infection preventionist competency model. Association for Professionals in Infection Control and Epidemiology website. http://www.apic.org/Professional-Practice/Infection_preventionist_IP_competency_model. Published 2012. Accessed September 1, 2014.

47. Stricof RL, Schabses KA, Tserenpuntsag B. Infection control resources in New York State hospitals, 2007. Am J Infect Control 2008;36:702-705.

48. Dawson SJ. The role of the infection control link nurse. J Hosp Infect 2003;54:251-257.

49. Wright J, Stover BH, Wilkerson S, Bratcher D. Expanding the infection control team: development of the infection control liaison position for the neonatal intensive care unit. Am J Infect Control 2002;30:174-178.

50. Teare EL, Peacock A. The development of an infection control link-nurse programme in a district general hospital. J Hosp Infect 1996;34:267-278.

51. Ching TY, Seto WH. Evaluating the efficacy of the infection control liaison nurse in the hospital. J Adv Nurs 1990;15:1128-1131.

52. EHR Incentive programs. Centers for Medicare and Medicade Services website. https://www.cms.gov/Regulations-and-Guidance/ Legislation/EHRIncentivePrograms/index.html?redirect=/ ehrincentiveprograms. Published 2014. Accessed April 10, 2014.

53. Lin MY, Hota B, Khan YM, et al. Quality of traditional surveillance for public reporting of nosocomial bloodstream infection rates. JAMA 2010;304:2035-2041.

54. Shepard J, Hadhazy E, Frederick J, et al. Using electronic medical records to increase the efficiency of catheter-associated urinary tract infection surveillance for National Health and Safety Network reporting. Am J Infect Control 2014;42:e33-e36.

55. Woeltje KF, Lautenbach E. Informatics and epidemiology in infection control. Infect Dis Clin North Am 2011;25:261-270. 